\title{
Spawning behaviour of Arctic charr (Salvelinus alpinus): risk of sperm competition and timing of milt release for sneaker and dominant males
}

\author{
V. Sørum, L. Figenschou, G. Rudolfsen \& I. Folstad ${ }^{1)}$ \\ (Faculty of Bio-science, Fishery and Economy, University of Troms $\varnothing$, \\ N-9037 Tromsø, Norway)
}

(Accepted: 17 August 2011)

\begin{abstract}
Summary
A mismatch in timing between the release of male and female gametes in external fertilizers may lead to failed fertilization or, under sperm competition, reduced paternity. To quantify the actual synchrony of gamete release and the level of sperm competition we placed video cameras on two spawning grounds of a naturally spawning population of Arctic charr (Salvelinus alpinus). Females release eggs in response to courting (quivering) in less than $1 \%$ of the cases, yet to both dominant and sneaker males. That is, females initiated spawning with dominant males in $73.3 \%$ of the recorded spawning events. Although the actual spawning seems to be largely under female control, $55.6 \%$ of spawning events occur under sperm competition. The average time delay between dominant and sneaker males milt release under sperm competition is $0.68 \mathrm{~s}$. Thus, female reproductive decisions seem to be strongly influenced by male-male competition and this may have set the stage for the evolution and maintenance of the observed plasticity in ejaculate characteristics of male charr.
\end{abstract}

Keywords: Arctic charr, reproductive behaviour, spawning synchrony, sperm competition, female choice.

\section{Introduction}

Sperm competition occurs when sperm from different males interact before the fertilization of ova (Parker, 1970; Birkhead \& Møller, 1998). In species where sperm competition is common and little cryptic female choice

\footnotetext{
1) Corresponding author's e-mail address: ivar.folstad@uit.no 
is exerted, e.g., in external fertilizers, there is strong intrasexual selection on sperm traits (Hoysak \& Liley, 2001; Gage et al., 2004; Stoltz \& Neff, 2006; reviewed in Birkhead \& Møller, 1998; Taborsky, 1998, 2001). Here, mechanisms allowing more resources to be allocated to sperm production should be selected among subordinate males as subordinates are more likely to experience sperm competition than dominant males (Parker, 1998). Thus, to compensate for a disfavoured mating position, subordinate males should be selected for increasing sperm number and velocity, but with a trade off against sperm longevity (Parker, 1993). Traditionally sperm numbers has been thought to be the most important parameter for paternity in external fertilizers (Peterson \& Warner, 1998), however, recent work suggests that sperm velocity, i.e., sperm swimming speed may have a substantial impact. For example, in cod (Gadus morhua), a broadcast spawner, sperm velocity had the strongest impact on male fertilization success (Rudolfsen et al., 2008, Skjæråsen et al., 2009). Thus, both sperm numbers and sperm velocity might be of importance for male fitness in sperm competition.

The timing of gamete release is important for external fertilizers (Mjølnerød et al., 1998; Yeates et al., 2007), as the release of sperm must be timed to fit within the time window of receptiveness of the eggs. A mismatch between the release of male and female gametes may lead to reduced or failed fertilization, or, under sperm competition, reduced paternity share. It has been shown experimentally that asymmetry in sperm release can have significant consequences for male fertilization success (Yeates et al., 2007) and one should expect that there has been selection for behaviour(s) to synchronize gamete release when spawning under natural conditions. However, we are not aware of any studies that measure the possible differences in gamete release synchrony between individuals.

The Arctic charr (Salvelinus alpinus) has a lek-like mating system characterized by sperm competition and alternative reproductive tactics among males (Fabricius, 1953; Fabricius \& Gustavson, 1954; Sigurjónsdóttir \& Gunnarson, 1989). During the spawning season males aggregate at distinct lek sites (Skarstein \& Folstad, 1996; Liljedal et al., 1999; Liljedal \& Folstad, 2003; Figenschou et al., 2004) and when the sexually mature females arrive, males compete intensely over positioning and fertilization opportunities. That is, when a female arrive, one male try to guard the female from other males by aggressively chasing and biting other males approaching the female (pers. obs., http://naturweb.uit.no/amb/evolution/). Males court 
females by gliding alongside her while quivering with high frequency low amplitude waves (Fabricius, 1953; Sigurjónsdóttir \& Gunnarson, 1989; pers. obs.). Occasionally this type of stimulating behaviour from the male(s) leads to female egg release (Fabricius, 1953) and, thus, fertilization opportunities for both dominant and subordinate males (pers. obs.). That is, during spawning, the nearby often smaller and less aggressive males regularly dart into the spawning site that offers no protection against sneakers and release their milt. Sperm number and sperm velocity seem to be important for male fertilization success under sperm competition (Figenschou et al., 2007; Liljedal et al., 2008), and both traits are very plastic in charr (Rudolfsen et al., 2006; Serrano et al., 2006; Haugland et al., 2009), where subordinates show higher sperm production and higher sperm velocity than dominant males (Rudolfsen et al., 2006). Additionally, males that switch between reproductive tactics can rapidly adjust sperm traits according to status (Rudolfsen et al., 2006).

Dominant (i.e., guarding) and subordinate (i.e., sneaker) males may differ in synchrony of gamete release with the female and under sperm competition the relative time difference in point of milt release between the guarding and the sneaker(s) males may affect paternity. However, empiric studies of the actual spawning event are to a large extent missing. By using underwater video cameras in charr's natural spawning environment, we recorded male density at female selected spawning sites, the synchrony of gamete release between the female and the male, and the time delay experienced by sneaker males.

\section{Methods}

\subsection{Study site and video recordings}

The study was conducted during the spawning season (mid September 2006 and 2007) at Lake Fjellfrøstvatn, located at $69^{\circ} \mathrm{N}, 19^{\circ} \mathrm{E}, 125 \mathrm{~m}$ above sea level in Troms, northern Norway. The depth of the spawning grounds varies between 0.5 and $2 \mathrm{~m}$ (Figenschou et al., 2004) and the bottom substrate consists mostly of a thin layer of mud and algae over gravel and rocks (pers. obs.). The recordings were conducted using two Sony Handycam video cameras, equipped with Sony wide conversion lenses $(\times 0.6)$, placed in underwater housings, in addition to a watertight Oregon Scientific (ATC-2K) video 
camera. The video cameras were mounted on tripods and aimed at stationary females. To reduce human induced interference at the spawning grounds, the cameras were left undisturbed for the duration of the recording time (approximately $90 \mathrm{~min}$ ). Recordings from the Sony Handycam were filed on Mini DV tapes using a long play setting, and later copied to DVD's, whereas recordings from the Action camera were stored on a memory card before downloaded to a computer hard drive. The recordings were later analysed using Final Cut Express HD v3.0 (Copyright ( $)$ 2002-2005, Apple Computer), iMovie HD v6.0.3 (Copyright (C) 1999-2006, Apple Computer) and Apple DVD Player v5.0.3 (Copyright ( $2001-2008$, Apple).

Examples of these videos are provided as Supplementary Material that can be accessed via http://media.brill.nl/beh/148/9

\subsection{The spawning event and its definitions}

In total we recorded $69 \mathrm{~h}$ and $40 \mathrm{~min}$ of Arctic charr spawning behaviour and captured a total of 45 spawning events. Of the recorded events 25 were captured in 2006 and the remaining 20 events in 2007. We defined a spawning to have occurred when at least 6 different types of spawning behaviours had taken place. We adapted the following specifications from Fabricius (1953), Fabricius \& Gustavson (1954), Sigurjónsdóttir \& Gunnarson (1989), Satou et al. (1991), Fleming (1996):

1. The female lay close to the bottom substrate with an erected anal fin and the anterior part of the body pointing upwards (anchoring).

2. The female is courted by a male: i.e., a male is approaching from the back, gliding alongside the female while quivering. Both males and females can be the first to quiver.

3. The quivering gets stronger and both male and female gape and quiver vigorously. At this point the male and female genital tract is close to one another and both presumably release their gametes. Released milt can be observed as whitening of the water around the spawning site at this stage of the spawning.

4. Both the male and female propels forward, away from the chosen site. The male frequently holds a higher velocity and, thus, leave the female behind.

5. Both individuals swim slightly upwards - from the substrate with the head still pointing upwards.

6. The female returns to the spawning site in a short radius circle, probably to protect and/or cover the spawned eggs. 


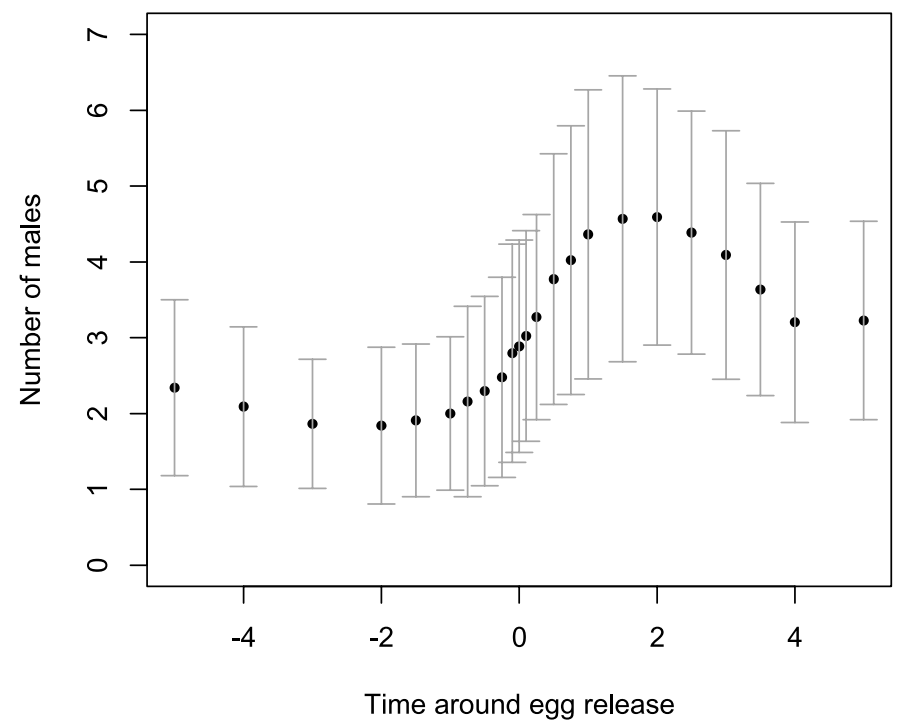

Figure 1. The mean number of males in proximity to the female at different times during the 10 -s spawning event $(N=44)$. Error bars denote $\pm 1 \mathrm{SD}$. Male density increase just prior to female egg release and decreases $2 \mathrm{~s}$ after.

\subsection{Male density, sperm competition and gamete release}

By counting the number of males that, at the actual spawning event, had some part of its body within the radius of approximately $25 \mathrm{~cm}$ (i.e., one fish length) from the female, we estimated male density at different time intervals between -5 and $5 \mathrm{~s}$ away from female gamete release (see Figure 1). Moreover, it is convenient to divide the level of sperm competition into two measurable categories (Parker et al., 1996): (i) risk of sperm competition, which is the average probability of any given male spawning with at least one other competing male, and (ii) intensity of sperm competition, which is the average number of competing males in the spawning events.

The females release of eggs in a spawning event is often difficult to observe, and in brown trout (Salmo trutta) females may trick males to release milt without releasing eggs by exhibiting all typical spawning behaviours except circling back to cover the eggs (Petersson \& Jarvi, 2001). Male milt release and female egg release was identified to occur when individual's mouth was fully opened (termed gaping, see also Fleming, 1996; Fitzpatrick et al., 2008). We have not observed milt release or oviposition without gaping behaviour, and we are not aware of any studies on salmonid species where this 
has been reported. Sperm competition was defined to have occurred when more than one male, in the same spawning event, followed the definitions of spawning behaviours. Asymmetry in male milt release was estimated by counting the number of video frames, between the first and the subsequent males gaping, using number of frames/frames per s. Due to uncertainty of when the mouth was fully opened in some spawning events, the best time resolution obtained was $0.1 \mathrm{~s}$.

\subsection{Guarding and sneaking tactics}

In the examined population, and in other Arctic charr populations, the adopted mating tactic among males seems to be plastic and size dependant (Figenschou et al., 2004; Rudolfsen et al., 2006). We identified which males that adopted guarding or sneaking mating tactics from the individual's behaviour. The larger male always adopted guarding behaviour, although some of the competitors could be approximately similar sized. In all the videocaptured spawning events there were initially one guarding male present that tried to monopolise the female and her spawning site by aggressively chasing other, smaller males. The competing males, which either; (i) dart into the spawning site and release their milt in competition with the guarding male, or (ii) stimulate the female to spawn when the guarding male were bound in aggressive male-male interactions, were defined as sneakers.

\subsection{Spawning synchrony}

By defining the moment of gaping as the time of gamete release, we estimated the synchrony between the female and the male gamete release. However, as individuals sometimes spawn with their head pointing away from the video camera or with one individual masking another, we were only able to estimate spawning synchrony in 34 out of the 45 recorded spawning events.

\subsection{Statistical analysis}

To avoid influencing the natural behaviour in the examined populations, we did not tag the individuals. Thus, the possibility of pseudoreplication is present in all observations. Yet, our observations are from two different years, from different spawning grounds and conducted throughout the one month long spawning period, rendering pseudoreplication less likely. 
We, therefore, chose to treat each spawning as an independent data point. Although sneakers mate opportunistically, we registered that females also spawned when courted by lone sneakers. Thus, we examined if spawning females $(N=17)$ showed preference for either guarding or sneaking males. Model fitting and estimates were obtained with linear mixed-effects (lmer) package lme4 in R (version 2.9.0, R Core Development Team, 2007), using logistic regression with a binominal distribution and logit function with female ID as random factor. Moreover, we measured if there were any differences in female preference for single versus multi-male spawning events (i.e., sperm competition). However, we did not observe any differences in female mating preferences for neither male reproductive tactic, nor single spawning events or sperm competition spawning events (data not shown, $p>0.08)$. Consequently, in the recorded spawning events $(N=45)$, statistical significance in frequencies was tested by chi-square $\left(\chi^{2}\right)$ tests.

Difference in spawning synchrony was evaluated with nonparametric tests when (i) we had low sample size, (ii) the variables did not fulfil the assumption of the homogeneous variances (Levene's test), or (iii) if the variables not showed a normal distribution of residuals. Estimates of spawning synchrony between female and male's gamete release differ from estimates of asymmetry in male milt release as sample sizes differ depending on the statistical approach. Moreover, we were not able to sample all variables for all events, so samples sizes vary throughout. Spawning synchrony in sperm competition between the guarding and the first sneaker male was tested with one sample $t$-test as the variables fulfilled the assumption for parametric tests. We used R (version 2.12.1 (2010-12-16), 2010 The R Foundation for Statistical Computing), STATISTICA (version 7.0, Stat Soft, Tulsa, OK, USA) and StatView for Windows 5.0.1, for the statistical procedures.

\section{Results}

\subsection{Male density at the spawning site}

Right before and during the spawning events there was an influx of males towards the spawning site. That is, the number of males, which ranged from 0 to 9 , showed a peak density $2 \mathrm{~s}$ after female egg release (Figure 1 ). Between -0.25 and $-0.1 \mathrm{~s}$ before female egg release, an increase in mean male density was observed (Wilcoxon signed-ranks test: $T=7.5, N=44$, 
$p<0.001$; see Figure 1); thus, pre-spawning behaviour seem to attract males towards the spawning site. The mean number of surrounding males, at the beginning of female egg release, was $2.9 \pm 1.4$ (mean $\pm \mathrm{SD}$, range 1-8), whereas male density $2.0 \mathrm{~s}$ after female egg release was $4.6 \pm 1.7$ (mean \pm SD, range 1-9). Males released milt from $0.15 \mathrm{~s}$ before female egg release to $1.9 \mathrm{~s}$ after female egg release. During this period $(\approx 2 \mathrm{~s})$ there was a significant mean increase of 1.8 male(s) around the female (Wilcoxon signed-ranks test: $T=5.5, N=44, p<0.001)$.

\subsection{Intensity and risk of sperm competition}

The level of sperm competition is measured as either intensity (number of males releasing milt), or risk (probability of experiencing sperm competition). There was sperm competition in 25 (55.6\%) out of 45 spawning events, suggesting that spawning events with more than one male present were not significantly more frequent than single male spawning events $\left(\chi_{1}^{2}=0.56\right.$, $p<0.46)$. Under sperm competition the mean number of males releasing milt was $2.6 \pm 0.7$ (mean $\pm \mathrm{SD}$, range $2-4, N=65)$. When also including the captured single male spawning events (all 45 recorded events), mean number of males releasing milt decreased to $1.88 \pm 0.96$ (mean \pm SD, range 1-4, $N=85$ ).

In total we registered 85 male milt releases during the 45 captured events: 65 of these were released in sperm competition (76.5\%) and 20 in single male spawning events. That is, more ejaculates were released in sperm competition than in single spawning events $\left(\chi_{1}^{2}=23.82, p<0.001\right)$. Moreover, 42 out of 51 sneaker male ejaculates $(82.4 \%)$ experienced sperm competition, compared to 23 out of 34 guarding male ejaculates (67.6\%); thus, guarding and sneaker males did not significantly differ in risk of sperm competition (Pearson's Chi-square test, $\chi_{1}^{2}=2.45, p=0.12$ ).

\subsection{Gamete synchrony, sperm competition and different male tactics}

On average the first sneaker males were ejaculating $0.48 \mathrm{~s}(\mathrm{SE} \pm 0.10, N=$ 25 ) after the guarding male (one sample $t$-test, $t_{24}=4.76, p<0.0001$ ). However, by pooling the time delay estimates from all sneaker males, from that of the guarding male, the overall mean delay for the average sneaker was $0.68 \mathrm{~s}(N=40)$. In sperm competition events, the guarding males ejaculated 


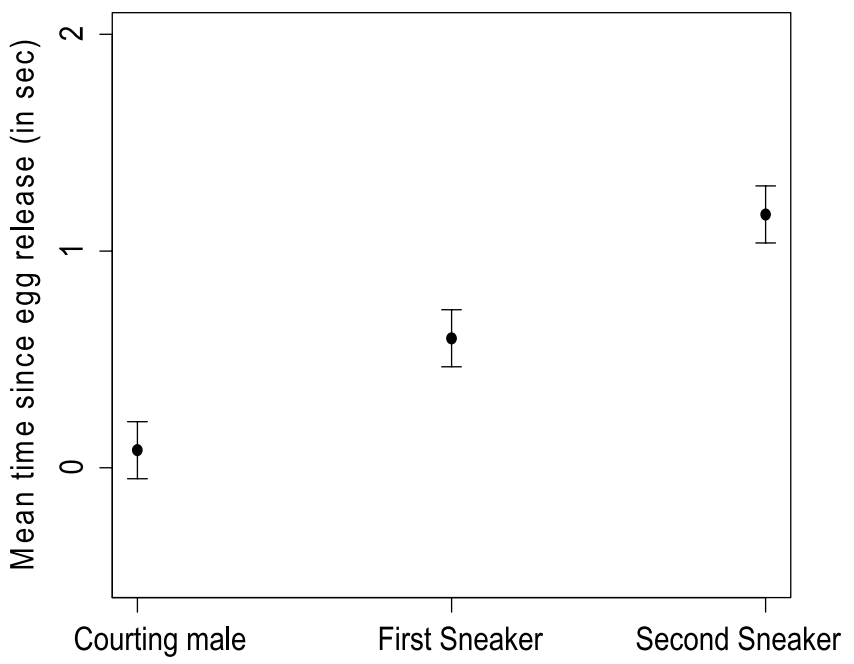

Figure 2. Courting male and sneaker males milt release under sperm competition relative to female egg release. Sample sizes differ among groups. Error bars denote \pm 1 SD.

before the sneaker males in 22 out of 25 events (88\%) and there was a significant difference in synchrony in milt release between the guarding male, first sneaker and second sneaker (Friedman ANOVA $\lambda^{2}=13.56$, $\mathrm{df}=2$, $p=0.00114, N=7$, see Figure 2).

Females surprisingly spawn when courted by sneaker males in 9 of the 20 single male spawning events (i.e., $45 \% ; \chi_{1}^{2}=2.00, p<0.65$ ). Moreover, in these single male spawning events, sneaker males milt release was significantly more in synchrony with female egg release than those of the guarding males (Figure 3; Mann-Whitney $U$-test, $U=4.0, p=0.014$; mean $\pm \mathrm{SD}=0.191 \pm 0.165(N=7)$ and $0.079 \pm 0.007 \mathrm{~s}(N=9)$. for guarding and sneaker males, respectively).

\subsection{Spawning initiated by guarding versus sneaker males}

Guarding males courted females more than subordinate males (in $64.8 \%$, i.e., 3163 times, of the recorded cases, $\left.\chi_{1}^{2}=428.5, p<0.001\right)$ and we observed that females spawned when being courted by guarding males in 33 out of 45 spawning events $(73.3 \%)$, which is significantly more frequent than when being courted by sneaker males $\left(\chi_{1}^{2}=9.8, p=0.002\right)$. However, the proportion of courting that resulted in female spawning was $1 \%$ for 


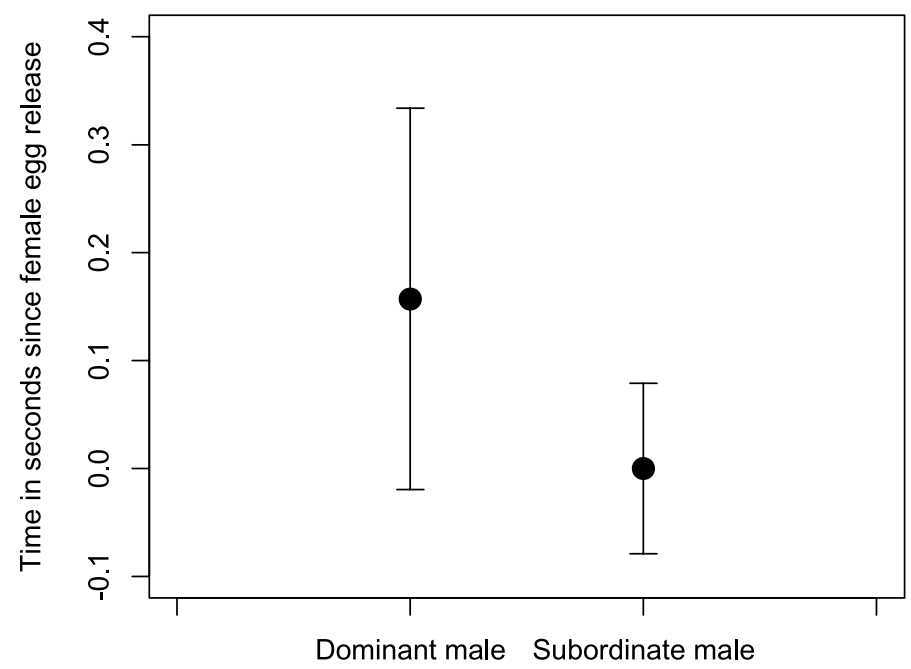

Figure 3. Guarding and sneaker males milt release in single male spawning events, relative to time of female egg release. $N=11$ for dominant males and $N=9$ for subordinate males.

Error bars denote $\pm 1 \mathrm{SD}$.

guarding males and $0.7 \%$ for subordinate males, suggesting low preference for guarding males.

\section{Discussion}

We observed that males frequently courted the females, but that females rarely responded to the stimuli by releasing eggs. When egg release occurred there was a high level of synchrony in gamete release between males and females with females normally releasing eggs first, quickly followed by milt release by the courting male and subsequently by the sneaker male(s). Although sneaker males experienced a higher risk of sperm competition than guarding males this difference was not significant. Yet, in single male spawning events sneaker males were more in synchrony with female egg release than guarding males.

Females chose to release eggs in response to male courting in less than $1 \%$ of the observed times and, as guarding males show the highest frequency of courting, they elicit significantly more spawning with females than subordinate males.

In roach (Rutilus rutilus), which has a similar mating system to that of charr, females differ in preferences for males (Wedekind, 1996), and females 
of external fertilizers may gain fitness by spawning with the most dominant males (Petersson \& Järvi, 1997; but see Reichard et al., 2007). This latter seems, however, not to be the case in charr where sperm from dominant males in split-brood fertilizations not result in higher quality larvae (i.e., larvae with more and redder yolk) than sperm from subordinate males ( $\mathrm{Fi}$ genschou et al., 2007). Still, the lowest density of males was observed just $2 \mathrm{~s}$ before female egg release (see Figure 1), suggesting that females may exert choice and release eggs when few subordinate males are present. Yet, as approximately $55 \%$ of the released eggs were released in sperm competition, with little female aggression directed towards males, female control seems limited. Also in roach, females show no resistance against multi-male fertilizations (Wedekind, 1996) and females may also exert choice and increase fitness by spawning when the probability of multiple males fertilizing the eggs is high, resulting in higher genetic variation in offspring (Jennions \& Petrie, 2000; Reichard et al., 2007).

On the other hand, dominant males may reduce the risk of sperm competition by stimulating the female to release eggs at low male densities. Still, there was a higher risk of experiencing sperm competition than avoiding it. Under sperm competition an average of 2.6 ejaculates was competing, whereas the overall mean decreases to 1.9 when also including the single male spawning events. According to theory (Parker et al., 1996), males should allocate most resources to sperm production when two males participate in a spawning event and decrease resource investments with increasing or decreasing number of competitors. In our study, the mean number of males engaged in sperm competition is, thus, close to what would favour the highest allocation of resources to sperm production.

Subordinate males should, everything else equal, experience sperm competition more frequently than guarding males (Parker, 1990). Sneaker males in the present study released 51 ejaculates in total; 9 in single spawnings and 42 in sperm competition. Yet, there was no significant difference in the probability of experiencing sperm competition between subordinates and dominants. According to theory, dominants should experience a loaded raffle and invest less in sperm production than subordinates (Parker, 1990; see Smith et al., 2009). This is in accordance with findings in other external fertilizers (Vladic \& Järvi, 2001; Gage et al., 2004; Skjæråsen et al., 2009) and has also previously been documented in charr, where rapid shifts in dominance relationships are accompanied with changes in sperm production and sperm 
velocity (Rudolfsen et al., 2006). Thus, our results suggest that a loaded raffle rather than the probability of sperm competition seems to be the best explanation for the differences in sperm investments observed between sneaker and guarding charr (Rudolfsen et al., 2006).

Although females usually were surrounded by a large number of competing males, 20 single male spawning events were captured. These events occurred while the other males, either the guarding or the sneaker males, were occupied with intra-sexual interactions that resulted in a delayed presence at the spawning site and no milt release. Premature male milt release may result from misinterpretation of female signals (Petersson \& Järvi, 2001) or, alternatively, from differences in risk assessment between sneaker and guarding males. That is, sneaker males may take greater risks than guarding males and may experience to release milt without females releasing eggs. However, we did not observe that neither sneaker nor guarding males released milt without female gaping. Moreover, we did not find any difference among the number of guarding and sneaker males that released milt before females released eggs. Yet, when males spawned alone with the female, sneaker males released their gametes more in synchrony with females than guarding males. Releasing milt just before the female releases eggs may result in an increased share of paternity as the eggs will be released onto already activated sperm in the water (Fitzpatrick \& Liley, 2008). Thus, a sneaker male's lack of synchrony in sperm competition events seems not caused by sneaker male's lack of ability to synchronise, but rather caused by the guarding male's mate guarding, preventing sneakers from releasing gametes in synchrony with the female.

A male's paternity share in sperm competition has previously been estimated from his rank order and proximity to the spawning female (Schroder, 1982; Gross, 1985; Fleming \& Gross, 1994; Fleming et al., 1996; Jacob et al., 2009). We observed an increased number of sneaker males in the immediate proximity of the female and the guarding male, immediately before egg release. This suggests that sneaker males, ahead of time, are able to identify, probably from the female and the guarding male's behaviour, that spawning will occur. This facilitates positioning among sneakers and may, thus, explain the relatively short delay in sneakers milt release. That is, in sperm competition, the guarding males released gametes more synchronous with the female compared to sneaker males, but the mean time delay in milt 
release from the guarding to the average sneaker was only $0.68 \mathrm{~s}$. For external fertilizers, sperm of the first male are believed to have precedence over sperm of males attending later in the same spawning event. For example, in Atlantic salmon (Salmo salar), a 2.0-s delay in sperm release caused significant reductions in paternity, with second males achieving only $30 \%$ fertilization success, against an expected 50\% (Yeates et al., 2007). However, for a species spawning in still water, a 0.68 -s delay in sperm release among sneakers may possibly be compensated for by the sneakers higher initial sperm velocity and their higher sperm numbers (Rudolfsen et al., 2006; Serrano et al., 2006; Haugland et al., 2009).

The captured spawning events indicate that the actual spawning seems to be largely under female control, implying opportunities for female choice. However, as sperm competition is common both for guarding and sneaker males; and as synchrony in gamete release are high, also for sneakers, female reproductive decisions seem to be strongly influenced by male-male competition. This may have set the stage for the evolution of the observed reproductive plasticity in male charr.

\section{Acknowledgement}

Two anonymous referees gave constructive comments that improved this presentation. The complete set of videos is available from the authors.

\section{References}

Birkhead, T.R. \& Møller, A.P. (eds) (1998). Sperm competition and sexual selection. Academic Press, London.

Fabricius, E. (1953). Aquarium observations on the spawning behavior of the charr Salmo alpinus. - Rep. Inst. Freshwater. Res. 35: 14-48.

Fabricius, E. \& Gustavson, K.J. (1954). Further aquarium observations on the spawning behavior of the charr Salmo alpinus. - Rep. Inst. Freshwater. Res. 35: 58-104.

Figenschou, L., Folstad, I. \& Liljedal, S. (2004). Lek fidelity of male Arctic charr. - Can. J. Zool. 82: 1278-1284.

Figenschou, L., Rudolfsen, G. \& Folstad, I. (2007). Females do not show apparent benefits from exposing their eggs to sperm from dominant males. - J. Fish Biol. 71: 284-289.

Fitzpatrick, J.L. \& Liley, N.R. (2008). Ejaculate expenditure and timing of gamete release in rainbow trout Oncorhynchus mykiss. - J. Fish Biol. 73: 262-274.

Fleming, I.A. (1996). Reproductive strategies of Atlantic salmon: ecology and evolution. Rev. Fish Biol. Fish. 6: 379-416. 
Fleming, I.A. \& Gross, M.R. (1994). Breeding competition in Pacific salmon (Coho: Oncorhynchus kisutch): measures of natural and sexual selection. - Evolution 48: 637657.

Fleming, I.A., Jonson, B., Gross, M.R. \& Lamberg, A. (1996). An experimental study of the reproductive behaviour and success of farmed and wild Atlantic salmon (Salmo salar). - J. Appl. Ecol. 33: 893-905.

Gage, M.J.G., Macfarlane, C.P., Yeates, S., Ward, R.G., Searle, J.B. \& Parker, G.A. (2004). Spermatozoal traits and sperm competition in Atlantic salmon: relative sperm velocity is the primary determinant of fertilization success. — Curr. Biol. 14: 44-47.

Gross, M.R. (1985). Disruptive selection for alternative life histories in salmon. - Nature 313: 47-48.

Haugland, T., Rudolfsen, G., Figenschou, L. \& Folstad, I. (2009). Sperm velocity and its relation to social status in Arctic charr (Salvelinus alpinus). - Anim. Reprod. Sci. 115: 231-237.

Hoysak, D.J. \& Liley, N.R. (2001). Fertilization dynamics in sockeye salmon and comparison of sperm from alternative male phenotypes. - J. Fish Biol. 58: 1286-1300.

Jacob, A., Evanno, G., Renai, E., Sermier, R. \& Wedekind, C. (2009). Male body size and breeding tubercles are both linked to intrasexual dominance and reproductive success in the minnow. - Anim. Behav. 77: 823-829.

Jennions, M.D. \& Petrie, M. (2000). Why do females mate multiply? A review of the genetic benefits. - Biol. Rev. 75: 21-64.

Liljedal, S. \& Folstad, I. (2003). Milt quality, parasites, and immune function in dominant and subordinate Arctic charr. - Can. J. Zool. 81: 221-227.

Liljedal, S., Folstad, I. \& Skarstein, F. (1999). Secondary sex traits, parasites, immunity and ejaculate quality in the Arctic charr. — Proc. Roy. Soc. Lond. B: Biol. 266: 1893-1898.

Liljedal, S., Rudolfsen, G. \& Folstad, I. (2008). Factors predicting male fertilization success in an external fertilizer. - Behav. Ecol. Soc. 62: 1805-1811.

Mjølnerød, I.B., Fleming, I.A., Refseth, U.H. \& Hindar, K. (1998). Mate and sperm competition during multiple-male spawnings of Atlantic salmon. - Can. J. Zool. 76: 0-75.

Parker, G.A. (1970). Sperm competition and its evolutionary consequences in insects. - Biol. Rev. Cambridge Phil. Soc. 45: 525-567.

Parker, G.A. (1990). Sperm competition games: raffles and roles. — Proc. Roy. Soc. Lond. B: Biol. 242: 120-126.

Parker, G.A. (1993). Sperm competition games: sperm size and sperm number under adult control. - Proc. Roy. Soc. Lond. B: Biol. 253: 245-254.

Parker, G.A. (1998). Sperm competition and the evolution of ejaculates: towards a theory base. - In: Sperm competition and sexual selection (Birkhead, T.R. \& Møller A.P., eds). Academic Press, London, p. 3-45.

Parker, G.A., Ball, M.A., Stockley, P. \& Gage, M.J.G. (1996). Sperm competition games: individual assessment of sperm competition intensity by group spawners. — Proc. Roy. Soc. Lond. B: Biol. 263: 1291-1297.

Petersson, E. \& Järvi, T. (1997). Reproductive behaviour of sea trout (Salmo trutta) - the consequences of sea-ranching. - Behaviour 134: 1-22.

Petersson, E. \& Järvi, T. (2001). "False orgasm" in female brown trout: trick or treat? Anim. Behav. 61: 497-501.

Peterson, C.W. \& Warner, P.R. (1998). Sperm competition in fishes. — In: Sperm competition and sexual selection (Birkhead, T.R. \& Møller, A.P. eds). Academic Press, London, p. 435-463. 
Reichard, M., Le Comber, S.C. \& Smith, C. (2007). Sneaking from a female perspective. Anim. Behav. 74: 679-688.

Rudolfsen, G., Figenschou, L., Folstad, I., \& Kleven, O. (2008). Sperm velocity influence paternity in the Atlantic cod (Gadus morhua L.). - Aquacult. Res.: 1-5.

Rudolfsen, G., Figenschou, L., Folstad, I., Tveiten, H. \& Figenschou, M. (2006). Rapid adjustments of sperm characteristics in relation to social status. - Proc. Roy. Soc. Lond. B: Biol. 273: 325-332.

Satou, M., Shiraishi, A., Matsushima, T. \& Okumoto, N. (1991). Comunication during spawning behavior in the himé salmon (landlocked red salmon, Oncorhynchus nerka). J. Comp. Physiol. A 168: 417-428.

Schroder, S.L. (1982). The influence of intrasexual competition on the distribution of chum salmon in an experimental stream. - In: Salmon and trout migratory behavior (Brannon, E.L. \& Salo, E.O., eds). University of Washington Press, Seattle, WA, p. 275-285.

Serrano, J.V., Folstad, I., Rudolfsen, G. \& Figenschou, L. (2006). Do the fastest sperm within an ejaculate swim faster in subordinate than in dominant males of Arctic char? - Can. J. Zool. 84: 1019-1024.

Sigurjónsdóttir, H. \& Gunnarson, K. (1989). Alternative mating tactics of Salvelinus alpinus, in Tingvallavatn, Iceland. — Environ. Biol. Fish. 26: 159-176.

Skarstein, F. \& Folstad, I. (1996). Sexual dichromatism and the imunocompetence handicap: an observational approach using Arctic charr. - Oikos 76: 359-369.

Skjæråsen, J.E., Mayer, I., Meager, J.J., Rudolfsen, G., Karlsen, Ø., Haugland, T. \& Kleven, O. (2009). Sperm characteristics and competitive ability in farmed and wild cod. Mar. Ecol. Prog. Ser. 375: 219-228.

Smith, C., Pateman-Jones, C., Zieba, G., Przybylski, M. \& Reichard, M. (2009). Sperm depletion as a consequence of increased sperm competition risk in the European bitterling, Rhodeus amarus. - Anim. Behav. 77: 1227-1233.

Stoltz, J.A. \& Neff, B.D. (2006). Sperm competition in a fish with external fertilization: the contribution of sperm number, speed and length. — J. Evol. Biol. 19: 1873-1881.

Taborsky, M. (1998). Sperm competition in fish: "bourgeois" males and parasitic spawning. — Trends Ecol. Evol. 13: 222-227.

Taborsky, M. (2001). The evolution of bourgeois, parasitic, and cooperative reproductive behaviours in fishes. - J. Hered. 92: 100-110.

Vladic, T.V. \& Järvi, T. (2001). Sperm quality in the alternative reproductive tactics of Atlantic salmon: the importance of the loaded raffle mechanism. - Proc. Roy. Soc. Lond. B: Biol. 268: 2375-2381.

Wedekind, C. (1996). Lek-like spawning behaviour and different female mate preferences in roach (Rutilus rutilus). - Behaviour 133: 681-695.

Yeates, S., Searle, J., Ward, R.G. \& Gage, M.J. (2007). A two-second delay confers firstmale fertilization precedence within in vitro sperm competition experiments in Atlantic salmon. — J. Fish Biol. 70: 318-322.

\section{Supplementary material}

The video (accessible via http://media.brill.nl/beh/148/9) shows:

1. Social status: A dominant male guarding a female from sneaker males 
2. Spawning 1: A guarding male spawn without sperm competition

3. Spawning 2: A guarding male spawn in sperm competition with three sneaker males

4. Spawning 3: A sneaker male spawn without sperm competition. 